\title{
Is Europe Really Battling Obesity?
}

\author{
Gema Frühbeck \\ Department of Endocrinology and Nutrition, Clínica Universidad de Navarra, University of Navarra, CIBERobn, \\ Instituto de Salud Carlos III, Pamplona, Spain
}

Several activities in the European Parliament in Strasbourg bringing together patient, scientific and political communities served to launch the first ever European Obesity Day (EOD) on May 22, 2010 to raise awareness of the need for action at the European level. In the 27 member states of the European Union approximately $60 \%$ of adults and $20 \%$ of school-age children are overweight or obese, with experts estimating that 150 million adults and 15 million children will be obese by 2010 in the 53 member states of the World Health Organization (WHO) European Region [1, 2]. These are challenging figures, and the next years will be a critical period especially for testing our collective ability to limit the spread and impact of obesity.

Obesity is already changing the epidemiology and natural course of many other diseases. One of the most sinister features of childhood obesity is the development of type 2 diabetes [2]. Given that cardiovascular risk markers are already evident in obese children, diabetes will worsen the clinical impact. Fatty liver has long been recognised in association with human obesity, but its significance as a cause of cirrhosis and liver failure in the long term has only recently been appreciated. The same is true for certain types of cancer with proven robust associations with obesity. No wonder that pessimism is setting in influenced by a sense of defeatism. Much is already being done, but our current best is not good enough, and new resources have to be harnessed and exploited. Although the European Parliament and the WHO have repeatedly drawn attention to this problem (fig. 1), the ultimate translation to action is still needed. Undoubtedly, policy makers play a key role in halting the further development of obesity. Whilst having to stand up against the high expectations from the general public as well as health professionals, medical resources are unrealistic to tackle the problem. On the one hand, politicians may need to be 'compliant' to the driving forces of the current economic market. Political messages have to counteract the persuasive and seducing voices of the big industrial players.
Moreover, public health actions of specific governments will not be looked at until the end of their stay in office. Thus, frequently, the delivery of official documents rather than the evaluation of real health outcomes are prioritised.

The treatment and prevention of obesity remain the thorniest issues and the greatest unmet needs. In purely energetic terms, obesity holds little mystery as it simply represents the excess of energy intake over expenditure. In humans, further layers of complexity to the genetic-environmental interaction are added by the numerous psychological, social and cultural factors that shape eating behaviour and physical activity $[3,4]$. However, from a pragmatic point of view it can be argued that we already know enough about obesity to make reasonable attempts to treat the disease. Noteworthy, evidence that weight loss, even if only $5-10 \%$, significantly decreases mortality, improves lipid profile, insulin resistance, hypertension and other cardiovascular diseases, osteoarthritis as well as other chronic diseases, and decreases the risk for developing cancer is derived from numerous studies carried out decades ago, but also from more recently performed randomised clinical trials such as the US Diabetes Prevention Program, the Finnish Diabetes Prevention Study, and the Look AHEAD trial etc. [5-10]. A 58\% reduction in new cases of type 2 diabetes has been observed in the lifestyle intervention groups with weight loss being the dominant predictor of diabetes risk in these groups. For every kilogram of weight loss, diabetes was reduced by $13 \%$. Modest weight loss also reduced the need of diabetes and antihypertensive medication. Analogous results have been obtained with trials of hypertension prevention showing that with even a modest weight loss change a major impact on mortality can be achieved.

Health professionals face a clinical inertia characterised by the lack of attention paid to obesity in the medical curricula [11], failed opportunities for diagnosis in specialised consultation, and the inclination to treat the consequences of obesity without specifically addressing the importance of weight loss

\section{KARGER}

Fax +497614520714

Information@Karger.de

www.karger.com (c) 2010 S. Karger GmbH, Freiburg

Accessible online at:

www.karger.com/ofa
Gema Frühbeck, R Nutr MD PhD

Department of Endocrinology and Nutrition

Clínica Universidad de Navarra, University of Navarra

CIBERobn, Instituto de Salud Carlos III

Avda. Pio XII, 36, 31008 Pamplona, Spain

gfruhbeck@unav.es 
- EU Platform for Action on Diet, Physical Activity and Health (2005)

Platform with the aim to provide a common forum for all interested actors at European level where they can explain their plans to contribute concretely to the pursuit of healthy nutrition, physical activity and the fight against obesity, and where these plans can be discussed, their outcomes and experience reported and reviewed. Stakeholders at a European level voluntarily commit to contain or reverse current trends in overweight and obesity.

http://ec.europa.eu/health/ph_determinants/life_style/nutrition/platform/docs/eu_platform_mon-framework_en.pdf

- $\quad$ Green Paper Promoting Healthy Diets and Physical Activity (2005)

Recognition that unhealthy diets and lack of physical activity are the leading causes of avoidable illness and premature death in Europe, and that the rising incidence of obesity is a major public health concern for the countries of the European Union. The Council called on the Member States and the Commission to devise and implement initiatives aimed at promoting healthy diets and physical activity. It accordingly called for the development of strategies entailing a multi-stakeholder approach with action being taken at local, regional, national and European levels. The aim is to gather information with a view to giving a European dimension to the battle against obesity, in terms of support for and coordination of the existing national measures.

http://europa.eu/legislation_summaries/public_health/health_determinants_lifestyle/c11542b_en.htm

- WHO European Charter on Counteracting Obesity (2006)

WHO European Ministerial Conference stating that obesity is a global public health problem and acknowledging the role that European action can play in setting an example and thereby mobilizing global efforts. Adoption as a matter of policy the commitment to strengthen action on counteracting obesity and also call on all partners and stakeholders to take stronger action against obesity. Recommendations to continue to be focused on preventing obesity in people who are already overweight and thus at high risk, and on treating the disease of obesity as well as to introduce timely identification and management of overweight and obesity in primary care, provision of training for health professionals in the prevention of obesity issuing clinical guidance for screening and treatment.

www.euro.who.int/en/who-we-are/policy-documents/european-charter-on-counteracting-obesity

- $\quad$ European Parliament Resolution on the Commission's Green Paper (2007)

Through this Resolution the Commission reinforced the messages and intended to trigger debate on initiatives geared towards preventing obesity. The primary objective is to create conditions under which the best practices can be adopted throughout Europe. Call to recognise obesity as a chronic disease and to acknowledge the essential role of health professionals. http://www.europarl.europa.eu/sides/getDoc.do? type $=$ TA\&language $=$ EN\&reference $=$ P6-TA-2007-0019

- WHO European Action Plan for Food and Nutrition Policy 2007-2012 (2007)

The WHO sets out practical steps for governments especially related to progress in reversing overweight and obesity in children and obesity that should be achievable in most countries in the next $4-5$ years reversing the trend by 2015 at the latest.

www.euro.who.int/en/what-we-do/health-topics/diseases-and-conditions/obesity/publications/pre-2009/who-european-actionplan-for-food-and-nutrition-policy-2007-2012

- White Paper: A Strategy for Europe on Nutrition, Overweight and Obesity (2007)

The purpose of the White Paper is to set out an integrated EU approach to contribute to reducing ill health due to poor nutrition, overweight and obesity. The Paper builds on recent initiatives undertaken by the Commission in particular the EU Platform for Action on Diet, Physical Activity and Health and the Green Paper. EU strategy advocating a multi-stakeholder approach to prevent overweight and obesity through self-regulation and voluntary initiatives rather than legislation. Actions should aim to address the root causes of the health related risks. The actions described are intended to work across government policy areas and at different levels of government using a range of instruments including legislation, networking, public-private approaches, and to engage the private sector and civil society. Monitoring will be essential over the coming years. Advice that 'European and national clinical professional bodies should develop proposals to strengthen the training of health professionals with regard to nutrition and physical activity related factors for ill health'. The Commission states that the trend of increases in overweight and obesity should be possible to reverse by 2015 at the latest. www.fp7.org.tr/tubitak_content_files//268/dokumanlar/White_Paper_on_A_strategy_for_Europe_on_nutrition_overweight_a nd_obesity_related_health_issues.pdf

- High Level Group on Nutrition (2007)

The White Paper foresaw this group gathering high-level national civil servants from Member States to share best practice to facilitate effective exchange of policy ideas and practices between Member States and to improve liaison between the EU Platform for Action on Diet, Physical Activity and Health and representatives of national governments, enabling relevant public-private partnership possibilities to be quickly identified and agreed upon. A stronger government role in counteracting obesity fosters a more balanced debate and ensures closer co-operation between public and private spheres, as well as promoting effective actions that are more swiftly shared across the EU.

http://ec.europa.eu/health/ph_determinants/life_style/nutrition/nutrition_hlg_en.htm

- European Parliament Resolution on the Commission's White Paper (2008)

Call on the Commission to promote best medical practices and studies comparing and evaluating the effectiveness of different interventions, including psychosocial research. Advises that people should have access to appropriate treatment under their national systems and that health professionals should be aware of their role. Calls, for more tangible measures especially targeted at children and at-risk groups.

www.europarl.europa.eu/sides/getDoc.do?type $=$ TA\&language $=$ EN\&reference $=$ P6-TA-2008-0461

Fig. 1. Panel summarising key EU and WHO obesity-related policy initiatives in the last years.
Progress Report on the EU strategy (2010)

The European Commission will assess in 2010 the various measures taken by industry and determine whether other approaches are also required following an internal political evaluation within the Directorate General for 'Health and Consumer Protection' (SANCO). A Progress Report is due to be published in the last months of 2010 ahead of a Final Report in 2013.

http://ec.europa.eu/dgs/health_consumer/index_en.htm 
[12]. Both food- and activity-related environmental changes are mandatory for any response to support behaviour change. The obesogenic environment should be minimised with changes in transport infrastructure and urban design. Broadly based societal interventions are needed to combat obesity at the same time as stimulating reflection on the potential response of society as a whole. Initiatives that are more likely to affect multiple pathways within the origin of obesity development in a sustainable way should be addressed. Creating demand for such change may rely on aligning the benefits with those arising from broader social and economic goals.

Obesity should be a top priority, with increased political commitment and prioritisation. The summarised evidence highlights the critical need for concerted, coordinated and specific strategies against obesity. The notion of a united front of patients, health professionals, and policy-makers is important, but a truly successful line-up needs to bring in other powerful key players, namely the industrial giants selling food and drink, cars, and screen-based entertainment. We already lost the first battle, which was halting the epidemic in the 21st century. The EOD highlighted that it is worth fighting the next big battle and urges to do so via the 'European citizens initiative' [13]. Thanks to the Lisbon Treaty, European citizens have now this new tool to participate in the shaping of EU policy; by collecting signatures from one million citizens, who are nationals of a significant number of Member States, the European Commission can directly be asked to take note and action. Thus, by simply registering one's support for the EOD charter a stimulus for creating a healthier Europe can be achieved.

\section{Disclosure}

The author is President-Elect of the European Association for the Study of Obesity (EASO).

\section{References}

1 World Health Organization (WHO): Obesity. www.euro.who.int/en/what-we-do/health-topics/ diseases-and-conditions/obesity.

2 Han JC, Lawlor DA, Kimm SYS: Childhood obesity. Lancet 2010;375:1737-1748.

3 Christakis NA, Fowler JH: The spread of obesity in a large social network over 32 years. N Engl J Med 2007;357:370-379.

4 Hinney A, Hebebrand J: Polygenic obesity in humans. Obes Facts 2008;1:35-42.

5 Knowler WC, Barett-Connor E, Fowler SE, et al Reduction in the incidence of type 2 diabetes with lifestyle intervention or metformin. $\mathrm{N}$ Engl J Med $2001 ; 344: 1343-1350$
6 Tuomilehto J, Lindström J, Eriksson JG, et al: Prevention of type 2 diabetes mellitus by changes in lifestyle among subjects with impaired glucose tolerance. N Engl J Med 2002;346:393-403.

7 Lindström J, Parikka PI, Peltonen M, et al: Sustained reduction in the incidence of type 2 diabetes by lifestyle intervention: follow-up of the Finnish Diabetes Prevention Study. Lancet 2006;366:16731679.

8 Jakicic JM, Jaramillo SA, Balasubramanyam A, et al: Effect of a lifestyle intervention on change in cardiorespiratory fitness in adults with type 2 diabetes: results from the Look AHEAD Study. Int J Obes 2009;33:305-316.
9 Williamson DA, Rejeski J, Lang W, et al: Impact of a weight management program on health-related quality of life in overweight adults with type 2 diabetes. Arch Intern Med 2009;169:163-171.

10 Redmon JB, Bertoni AG, Connelly S, et al: Effect of the Look AHEAD Study intervention on medication use and related cost to treat cardiovascular disease risk factors in individuals with type 2 diabetes. Diabetes Care 2010;33:1153-1158.

11 Hall JI: Obesity - a reluctance to treat? Obes Facts 2010;3:79-80.

12 Frühbeck G, Diez-Caballero A, Gómez-Ambrosi J, et al: Preventing obesity. Doctors underestimate obesity. BMJ 2003;326:102.

13 European Obesity Day (EOD) European Citizens' Initiative Petition. www.obesityday.eu/eu/en/european-citizens-initiative-petition. 